\title{
XIV. Rationale of the difficulty of separating plane surfaces by a blast, in certain cases
}

\section{R. Hare M.D.}

To cite this article: R. Hare M.D. (1828) XIV. Rationale of the difficulty of separating plane surfaces by a blast, in certain cases, Philosophical Magazine Series 2, 4:20, 94-95, DOI: $10.1080 / 14786442808674734$

To link to this article: http://dx.doi.org/10.1080/14786442808674734

曲 Published online: 10 Jul 2009.

Submit your article to this journal

Џll Article views: 2

Q View related articles 두 


\section{Prof. Hare's Rationale on the Difficulty of separating}

existence of such alloys of the metals of the earths as may burn into lava in the interior, the whole phænomena may be easily explained from the action of the water of the sea and air on those metals; nor is there any fact or any of the circumstances which I have mentioned in the preceding part of this paper, which cannot be easily explained according to that hypothesis. For almost all the volcanoes in the old world of considerable magnitude are near, or at no considerable distance from the sea: and if it be assumed that the first eruptions are produced by the action of sea water upon the metals of the earths, and that considerable cavities are left by the oxidated metals thrown out as lava, the results of their action are such as might be anticipated; for after the first eruptions, the oxidations which produce the subsequent ones may take place in the caverns below the surface; and when the sea is distant, as in the volcanoes of South America, they may be supplied with water from great subterranean lakes; as Humboldt states that some of them throw up quantities of fish.

On the hypothesis of a chemical cause for volcanic fires, and reasoning from known facts, there appears to me no other adequate source than the oxidation of the metals which form the bases of the earths and alkalies; but it must not be denied that considerations derived from thermometrical experiments on the temperature of mines and of sources of hot water, render it probable that the interior of the globe possesses a very high temperature: and the hypothesis of the nucleus of the globe being composed of fluid matter, offers a still more simple solution of the phænomena of volcanic fires than that which bas been just developed.

Whatever opinion may be ultimately formed or adopted on this subject, $I$ hope that these inquiries on the actual products of a volcano in eruption will not be without interest for the Royal Society.

XIV. Rationale of the Difficulty of separating Plane Surfaces by a Blast, in certain Cases. By R. HARE, M.D. Professor of Chemistry in the University of Pennsylvania.*

THE phænomenon above alluded to, is usually illustrated by means of two discs, into the centre of one of which, a tube is fastened, so that on blowing through the tube, the current is arrested by the other moveable disc. Under these circumstances, the moveable disc is not removed as would be naturally expected. Supposing the diameter of the discs to

* Communicated by the Author. 
be to that of the orifice as 8 to 1 , the area of the former to the latter must be as 64 to 1 . Hence if the discs were to be separated (their surfaces remaining parallel) with a velocity as great as that of the blast, a column of air must meanwhile be interposed 64 times greater than that which would escape from the tube during the interim. Consequently, if all the air necessary to preserve the equilibrium be supplied from the tube, the discs must be separated with a velocity as much less than that of the blast, as the column, required between them, is greater than that yielded by the tube; and yet the air cannot be supplied from any other source, unless a deficit of pressure be created between the discs, unfavourable to their separation.

It follows, then, that under the circumstances in question, the discs cannot be made to move asunder with a velocity greater than 1-64th of that of the blast. Of course all the momentum of the aërial particles which constitute the current through the tube, will be expended on the moveable disc, and the thin ring of air which exists around the orifice between the discs; and since the moveable disc can only move with 1-64th of the velocity of the blast, the ring of air in the interstice must experience nearly all the momentum of the jet, and must be driven outwards; the blast following it in various currents radiating from the common centre of the tube and discs. The effect of such currents in producing an afflux of the adjoining portions of any fluid in which they may be excited, is well known, having been successfully illustrated by Venturi. (See Nicholson's Journal, quarto series, vol. ii. p. 172.) Accordingly the afflux of air towards the discs counteracts the small velocity which the blast would communicate, and thus prevents their separation, and may even cause them to approach each other, if previously situated a small distance apart.

This rationale commences with the assumption, that the discs will remain nearly parallel. That there cannot be much deviation from parallelism must be evident; since any obliquity will make the opening greater on one side than on the other; and the jet proceeding with most force towards the widest opening, will increase the afflux of air upon the outer surface of the moveable disc in the part where the current is strongest, and thus correct the obliquity. 